\title{
Integrating declarative and imperative approach to model logistics service processes
}

\author{
Ying Wang, Lei Huang, Yi Guo \\ School of economics and Management, Beijing Jiaotong University (China) \\ yingw2002@,sina.com,lbuang@,bjtu.edu.cn,11113164@,bjtu.edu.cn
}

Received August 2012

Accepted February 2013

\section{Abstract:}

Purpose: There is a widespread recognition of the importance of correctly modeling service processes as an effective way to provide a comprehensive understanding of the process and to enhance the service quality to clients. Taking this into account, this paper aims to construct the logistics service process model using the integration of the declarative approach and imperative approach.

Design/methodology/approach: A methodology integrating the declarative and imperative process modeling approach is proposed for modeling the logistics service processes. Through investigation of the service departments and services involved, the process is decomposed into loosely-structured parts modeled by a declarative approach and highly structured parts modeled by an imperative approach. The loosely-structured and highly-structured parts are then integrated to form the model for the logistics service process.

Findings: Through a case study for a Chinese bulk port, the integrative method proves to be effective in modeling the loosely-structured logistics service processes. The result model is able to express the logistics regulations and corresponding rules across different organizations as well as the strict execution order of the process activities inside a particular organization. 
Originality/value: The model could be the starting point for further logistics service process investigation. Future work could be conducted for conformance checking of the logistics service process using the model as a reference model.

Keywords: logistics service process, process modeling, declarative approach, imperative approach

\section{Introduction}

The logistics industry is considered as a classic example of the service-based industries, which hold an increasingly dynamic and pivotal role in today's knowledge-based economies (Chapman, Soosay \& Kandampully, 2003). Transformed from the business concept of transportation to that of serving the entire logistical needs of customers, logistics services have to be customized by customer segments to deliver specific, flexible services to individual clients (Mentzer, Flint \& Hult, 2001; Reijers, 2003).

As a process-oriented business (Chow, Choy \& Lee, 2007; Rutner \& Langley Jr, 2000), logistics service is defined as the process of delivering products and/or services to customers, in a way that creates added value to customers. Superior logistics performance is considered related to simultaneous integration of internal and external operational processes (Rodrigues, Stank \& Lynch, 2004; Van der Veeken \& Rutten, 1998). Thus, there is a widespread recognition of the importance of correctly modeling service processes as an effective way to provide a comprehensive understanding of the process and to enhance the service quality to clients (Aguilar-Saven, 2004; Reijers, 2003). However, surprisingly few articles published in academic journals in this respect for logistics service process modeling.

This paper aims to construct the logistics service process model using the integration of the declarative approach and imperative approach. The remainder of this paper is structured as follows: Section 2 provides the state of the art of service process modeling in logistics. Followed by, the methodology is discussed in Section 3. Section 4 extensively elaborates the case study for a Chinese bulk port. Finally, Section 5 concludes the paper and discusses the future work.

\section{Service Process Modelling in Logistics: State of the Art}

In this part, the characteristics of logistics service are investigated and the port logistics serve processes are discussed in particular. Moreover, the imperative and declarative process modeling approaches are elaborated for their strengths and weaknesses. 


\subsection{Logistics Service}

The basic characteristics of logistics service are identified and summarized as follows:

- Better service performance is achieved through offering a wide variety of logistics services. Superior performance of logistics service is dependent on the manner in which LSPS leverage various resources, which can be either tangible or intangible. Besides, LSPs should differentiate themselves on the basis of their ability to satisfy the needs of customers for various logistics services (Lai, 2004).

- Logistics is an integrated process that involves a network of organizations. Collaborating with customers and suppliers is a first step toward service performance improvement (Stank, Keller, \& Daugherty, 2001). In essence, logistics is an integrative approach to the interaction of different processes and functions within a firm extended to a network of organizations for the purpose of cost reduction and customer satisfaction (Bichou \& Gray, 2004).

- Logistics service is a process that creates value (Mentzer, Rutner \& Matsuno, 1997; Rutner \& Langley Jr, 2000). Logistics represents a key bundle of resources that can provide the best comparative net value for the customers (Langley \& Holcomb, 1992). Logistics strategy should be directed towards relevant value-added logistics activities (Bichou \& Gray, 2004).

\subsection{Port Logistics Service Process}

A rich picture of the port logistics concept involves Ocean Shipping, Port Entrance, Stevedoring, Transition, Storage, Inland Transport Connection and Inland Transport, etc (Roh, Lalwani, \& Naim, 2007). As complex and multipart organizations, ports are very dissimilar and even within a single port the current or potential activities can be broad in scope and nature (Bichou \& Gray, 2004). Therefore, port logistics service is conducted across organizations in which institutions and functions often intersect at various levels.

As a typical service process, port logistics service process can be divided into primary processes which satisfy external customers of the port and support processes which satisfy only internal customers (Hill, Collier, Froehle, Goodale, Metters \& Verma, 2002). Primary processes are the core processes that create the core competencies of the port. The primary processes for port logistics service are often loosely structured and cross administrative boundaries, requiring high degree of flexibility. On the other hand, the processes inside a specific administrative organization are often highly-structured, requiring strict specification of the service procedure. 


\subsection{Imperative and Declarative Process Modeling Approaches}

A plethora of process modeling approaches has been proposed, including graph-based imperative approach and rule-based declarative approach (Lu \& Sadiq, 2007). Imperative approach strictly specifies how the process will be executed, while declarative approach implicitly defines the control-flow as all possibilities that do not violate any of the given constraints (Pesic, Schonenberg \& van der Aalst, 2007).

Petri net is a typical imperative process modeling language, with advantages of formal semantics despite the graphical nature and abundance of analysis techniques (Van der Aalst, 1998). However, a straightforward application of high-level Petri nets does not yield the desired result when used for modeling workflow processes due to problems with support for some workflow patterns. As an extension of Petri nets with additional features, YAWL (Yet Another Workflow Language) was proposed to facilitate the modeling of complex workflows (Van Der Aalst \& Ter Hofstede, 2005). Most workflow languages can be mapped onto YAWL without loss of control-flow details (Lohmann, Verbeek \& Dijkman, 2009).

Imperative modeling approach is considered not flexible enough to support loosely-structured processes. Therefore, the Declare framework was presented using a constraint-based declarative approach to support loosely-structured process models. Compared to an imperative model in which all possibilities have to be entered into the model by specifying its control-flow, a declarative model specifies a set of constraints as business rules that should be followed during the execution. As a result, the number of possible executions in a declarative process model is infinite as long as the constraints are obeyed (Pesic, et al., 2007; van der Aalst, Pesic \& Schonenberg, 2009).

\section{Methodology}

In this section, we present a methodology for modeling the logistics service processes by decomposing the processes into highly-structured and loosely-structured parts. Fig. 1 schematically illustrates the methodology.

First of all, the service departments and services conducted by each department are investigated. Since service processes inside a department are often highly-structured and those across different organizations are normally loosely-structured, the service process can be decomposed into the loosely-structured and highly-structured parts according to the service organization structure. What's more, the activities in the service process can be identified accordingly.

Next, service policies and regulations and the corresponding business rules are investigated and summarized. Business rules make the knowledge about implicitly present policies and regulations explicitly traceable. In this way, changes in policies and regulations can be traced back to the 
business processes, thus enhancing flexibility (Goedertier \& Vanthienen, 2006). Therefore, integration of complex process logic into process models as business rules using a declarative approach (Lu \& Sadiq, 2007) would support dynamic changes and provide a set of construction rules that enforce business constraints and policies (Krogstie, McBrien, Owens \& Seltveit, 1991; Zur Muehlen \& Indulska, 2010) for the service processes.

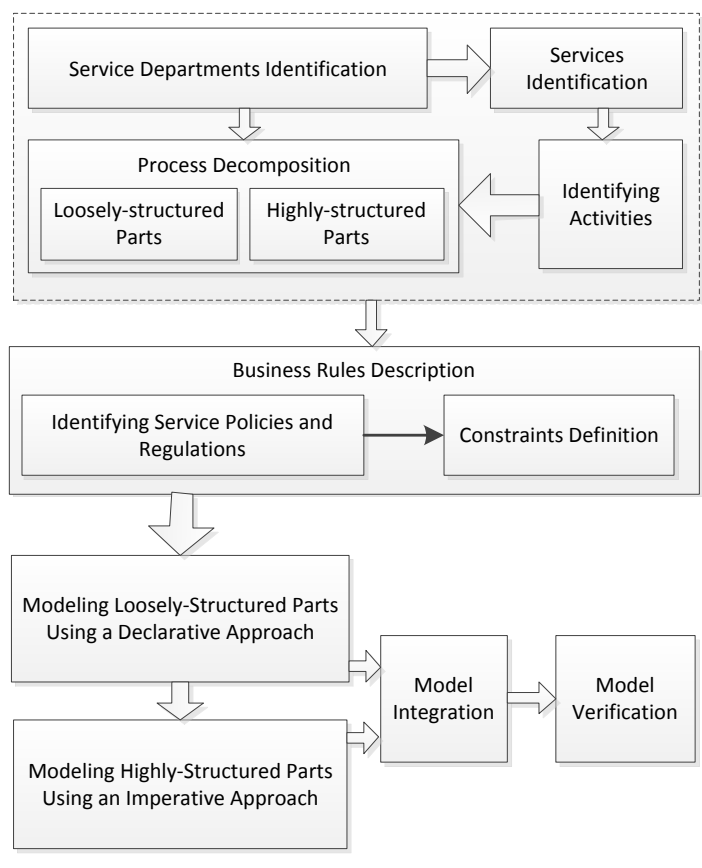

Figure 1. The methodology roadmap for modeling the logistics service processes by decomposing the processes into highly-structured and loosely-structured parts

Thirdly, we construct the model of the loosely-structured parts using a declarative approach while the highly-structured parts using an imperative approach. These parts are then mixed together to form an integrated process model for the complex logistics service process.

Lastly, the model is verified against dead activities and conflicting constraints by analyses of the states during process execution.

\section{A Case for a Chinese Port}

In this part, we elaborate the modeling of logistics service processes by a case study for a Chinese port.

\subsection{Primary logistics Service Processes for the Port}

Multiple levels of logistics services are provided by the modern port, including core services such as the cargo stevedoring and storage, auxiliary services such as towboat operation and the railway assemblage and distribution, and extended services such as cargo packing and processing, or warehouse sorting. 
Services for inward and outgoing cargo handling constitute the core logistics services for the port. On the one hand, bulk cargo may concentrate in the harbor by trucks, local vessels, or trains, and waited for the ships to put in the harbor and then those cargoes can be loaded and transported away by the ships. This is the process for inward cargo handling service. On the other hand, cargoes may be transported to the harbor by ships, discharged to the port warehouse, and then carried away from the port by trucks, local vessels, or trains. This is the process for outgoing cargo handling service. Thus, the inward and outgoing cargo handling service processes are the primary logistics service processes for the bulk port.

\subsection{Service Departments and Activities involved in the Process}

In this paper, the process for inward cargo handling service is selected for the analysis. The service departments involved in this process are illustrated in Table 1.

The process is then decomposed into loosely-structured and highly-structured parts according to the service organization structure:

\begin{tabular}{|l|l|}
\hline Service Departments & Services (Activities) \\
\hline Port Entrance & harbor entrance control \\
\hline Ship Scheduling Department & ship scheduling \\
\hline Human Resource Department & work planning \\
\hline Business Managers & contract signing \\
\hline \multirow{4}{*}{ Commercial Document Administration } & commercial documents management \\
\cline { 2 - 2 } & Ship arrival report \\
\cline { 2 - 2 } & Tally book input \\
\cline { 2 - 2 } & Assign contract to the tally book \\
\cline { 2 - 2 } & Loading certificate creation and checking \\
\hline Wagon Balance Department & cargo weighing \\
\hline Warehouse Department & tally sheet creation \\
\hline Cargo Inspector & cargo documents inspection \\
\hline Accounting Office & Billing \\
\hline
\end{tabular}

Table 1. Service departments involved in the inward cargo handling service process

- Most of the processes inside an individual service department are highly structured procedures. For example, the process for cargo weighing consists of two activities of "weigh the truck without cargoes" and "weigh the truck with cargoes", which follow a strict execution order between these two activities.

- The processes across different service departments are often loosely-structured. For instance, there is no strict order between the activity "Ship Forecast Report" and "Contract Signing".

- For some complex service departments such as the "commercial document administration" department, processes inside may also be loosely-structured. Thus, the activities for the declarative process model can be identified accordingly (see Table 1). 


\subsection{Service Policies and Regulations}

The service policies and regulations and the corresponding business rules in the inward cargo handling service process are investigated and summarized in Table 2 . The ConDec language defined in Declare framework is used as the constraint template to create the constraints. The formal specification of the constraint template is given as a Linear Temporal Logic formula (Pesic, Schonenberg \& Van Der Aalst, 2009). The constraints used in the case are illustrated as follows:

- $\operatorname{exactly1}(A)$

- $\quad$ "A" has to happen exactly once.

- precedence $(A, B)$

- " $B$ " has to be preceded by "A".

- $\quad$ " $B$ " can happen only after "A" had happened.

- $\operatorname{succession}(A, B)$

- After every " $A$ " there has to be at least one " $B$ ".

- " $B$ " has to be preceded by " $A$ ".

- " $B$ " can happen only after " $A$ " had happened.

- $\operatorname{not} \operatorname{succession}(A, B)$

- Before $B$ there cannot be $A$ and after $A$ there cannot be $B$.

\begin{tabular}{|l|l|l|}
\hline Rule ID & $\begin{array}{l}\text { Service Policies and Regulations } \\
\text { A contract has to be signed. }\end{array}$ & $\begin{array}{l}\text { Constraints } \\
\text { exactly1("Contract Signing") }\end{array}$ \\
\hline C. 2 & $\begin{array}{l}\text { Billing terms must be appointed } \\
\text { after the contract signed }\end{array}$ & $\begin{array}{l}\text { succession ("Contract Signing", "Appoint } \\
\text { Billing Terms to the Tally Book") }\end{array}$ \\
\hline C. 3 & $\begin{array}{l}\text { Loading certificate has to be } \\
\text { created after the contract signed }\end{array}$ & $\begin{array}{l}\text { succession ("Contract Signing", "Loading } \\
\text { Certificate Creation and Checking") }\end{array}$ \\
\hline C. 4 & $\begin{array}{l}\text { Billing terms must be appointed } \\
\text { to each tally book. }\end{array}$ & $\begin{array}{l}\text { succession ("Tally Book Input", "Appoint } \\
\text { Billing Terms to the Tally Book") }\end{array}$ \\
\hline C. 5 & $\begin{array}{l}\text { Ship arrivals must be reported } \\
\text { before the ship scheduling }\end{array}$ & $\begin{array}{l}\text { succession ("Ship Arrival Report", "Ship } \\
\text { Scheduling") }\end{array}$ \\
\hline C. 6 & $\begin{array}{l}\text { Work planning has to be started } \\
\text { after the ship scheduling. }\end{array}$ & $\begin{array}{l}\text { succession ("Ship Scheduling", "Work } \\
\text { Planning") }\end{array}$ \\
\hline C. 7 & $\begin{array}{l}\text { Cargo weighing can only start } \\
\text { after the work planning. }\end{array}$ & $\begin{array}{l}\text { precedence ("Work Planning", "Cargo } \\
\text { Weighing") }\end{array}$ \\
\hline C. 8 & $\begin{array}{l}\text { Cargo Documents has to be } \\
\text { inspected after tally sheet } \\
\text { creation. }\end{array}$ & $\begin{array}{l}\text { succession ("Tally Sheet Creation", } \\
\text { "Cargo Documents Inspection") }\end{array}$ \\
\hline C. 9 & $\begin{array}{l}\text { No cargo is allowed to be picked } \\
\text { up after cargo documents } \\
\text { inspection. }\end{array}$ & $\begin{array}{l}\text { not succession ("Cargo Documents } \\
\text { Inspection", "Cargo Weighing") }\end{array}$ \\
\hline C. 10 & $\begin{array}{l}\text { Cargo documents inspection } \\
\text { must be finished before billing. }\end{array}$ & $\begin{array}{l}\text { not succession ("Billing", "Cargo } \\
\text { Documents Inspection") }\end{array}$ \\
\hline C. 11 & $\begin{array}{l}\text { Billing can only start after the } \\
\text { cargo documents inspection. }\end{array}$ & $\begin{array}{l}\text { precedence ("Cargo Documents } \\
\text { Inspection", "Billing") }\end{array}$ \\
\hline C. 12 & $\begin{array}{l}\text { Cargo documents must be } \\
\text { inspected after the loading } \\
\text { certificate creation and checking }\end{array}$ & $\begin{array}{l}\text { succession ("Loading Certificate Creation } \\
\text { and Checking", " Cargo Documents } \\
\text { Inspection") }\end{array}$ \\
\hline C. 13 & $\begin{array}{l}\text { Tally sheets have to be created } \\
\text { after work planning }\end{array}$ & $\begin{array}{l}\text { succession ("Work Planning", "Tally } \\
\text { Sheet Creation") }\end{array}$ \\
\hline
\end{tabular}

Table 2. Constraints defined in the service process model 
Note that all of the constraints are mandatory except for C. 7. In reality, not all cargoes would be weighed, so it is up to the user to decide in which cases the "Cargo Weighing" would be conducted and in which not.

\subsection{The Model}

Firstly, we construct the model for the loosely-structured parts of the process using a declarative approach. As shown in Figure 2, each of the constraints represents one of the business rules mentioned in Table 2. By imposing business rules to the model with constraints, the model provides full support for compliance and flexibility. For example, the model does not impose strict order between "Ship Forecast Report" and "Contract Signing". This is in accordance with the process in reality that the contract may be signed either long before the ship arrival or after the ship arrival.

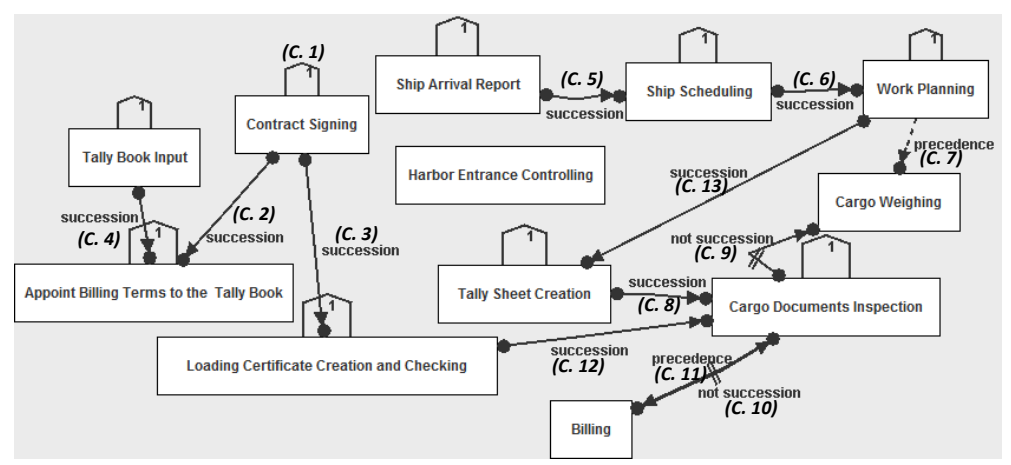

Figure 2. Modeling loosely-structured parts of the process using DECLARE
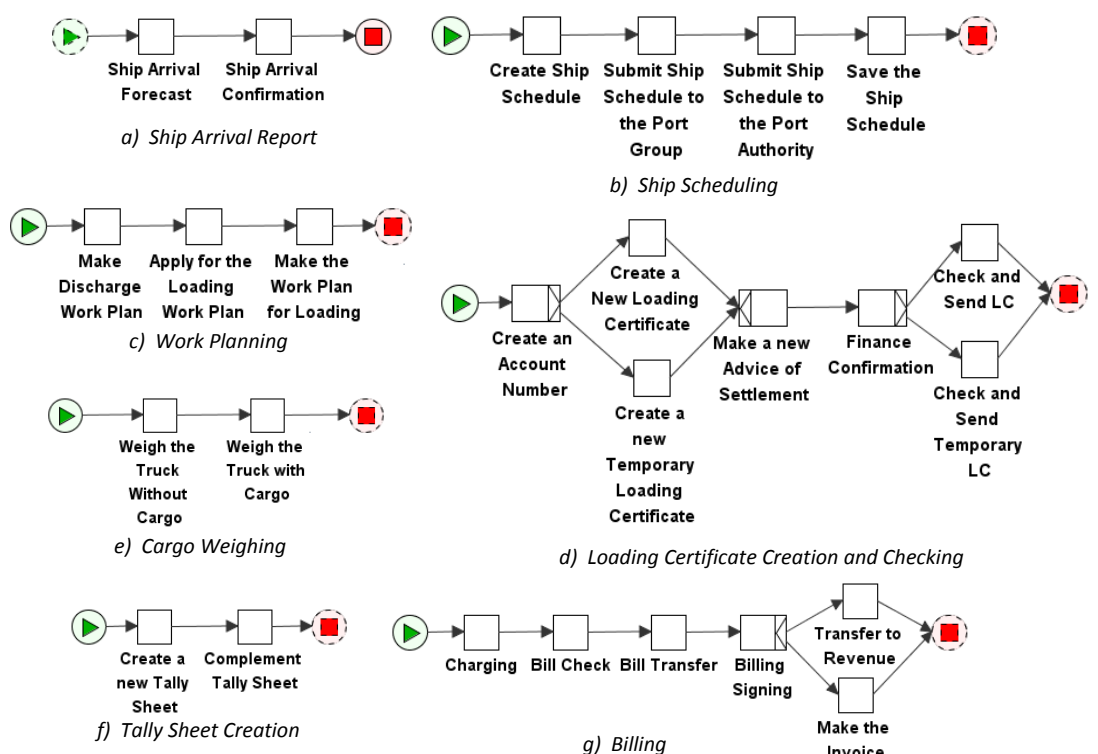

d) Loading Certificate Creation and Checking

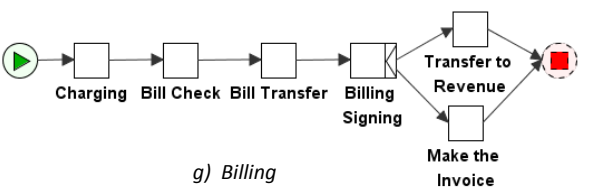

Figure 3. Modeling highly-structured parts of the process using YAWL

Next, the highly structured parts of the process are modeled by YAWL (see Figure 3). 
Finally, each of the highly-structured YAWL models of the process is subcontracted to the DECLARE service as a service consumer. This way the highly-structured and loosely-structured parts of the processes can be decomposed and arbitrarily mixed together for modeling the complex logistics service process.

\subsection{Model Verification}

Since the addition of constraints to a process model may cause errors that lead to problems at run-time, the loosely-structured parts of the model should be verified against dead activities and conflicting constraints.

Figure 4 shows the initial state of the loosely-structured model. It shows that the process can start with "Tally Book Input", "Contract Signing", "Ship Arrival Report", or "Harbor Entrance Controlling". Since the precedence constraint between "Work Planning" and "Cargo Weighing" is optional, a warning would be presented if the process start with this activity.

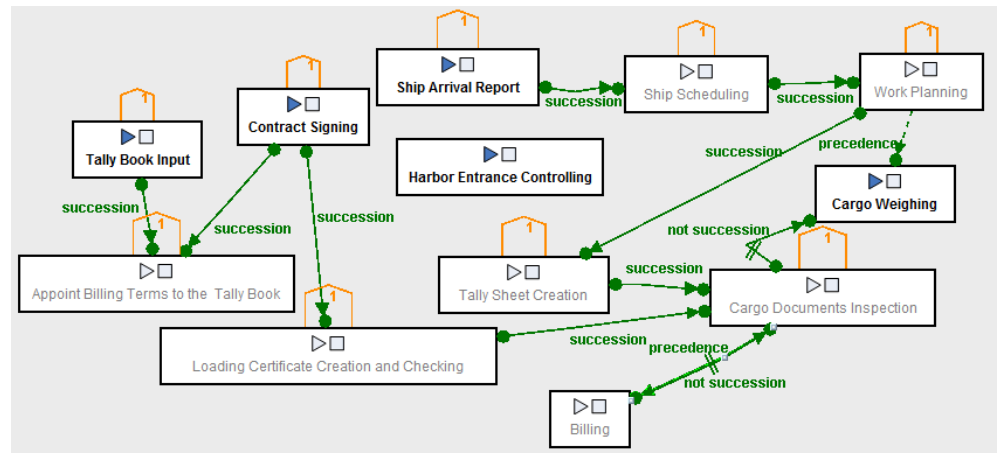

Figure 4. The initial state of the loosely-structured model

Further analysis shows that this model provides good support for both compliance and flexibility for the logistics service process. For example, cases that do not need weighing (see Figure 5) can be executed properly with this model. In addition, serious violation of the business rules, such as Loading Certificate creation without a contract cannot be enabled during the process execution (see Figure 6).

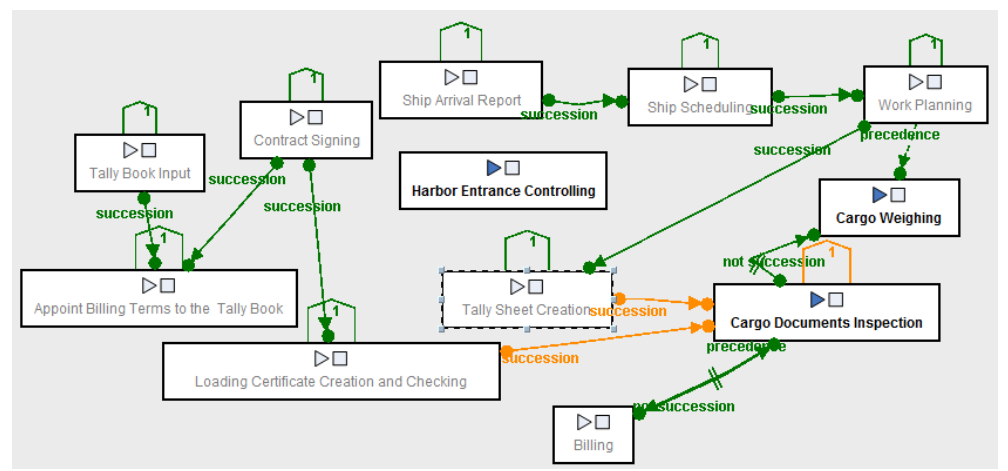

Figure 5. The state after "Tally Sheet Creation" without "Cargo Weighing" 


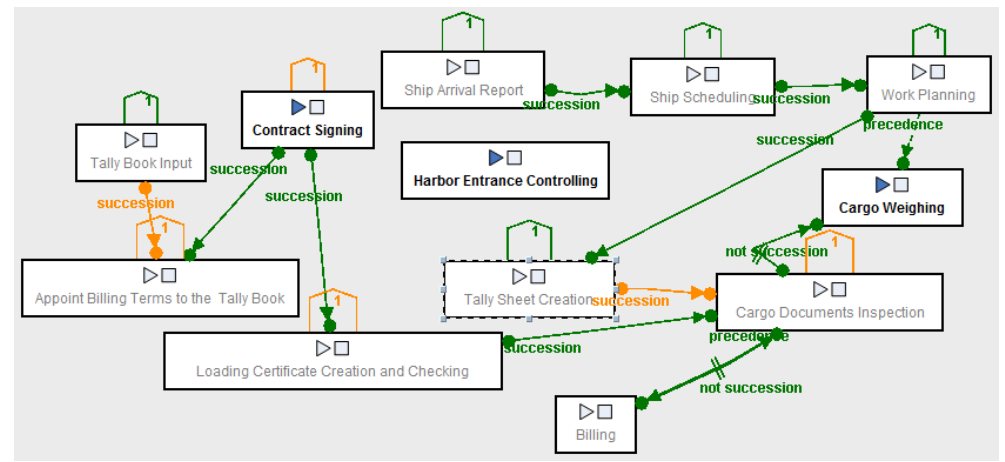

Figure 6. "Loading Certificate Creation and Checking" cannot be enabled without the contract

\section{Conclusion and Future Work}

In this paper, we present a methodology for modeling the logistics service processes by integrating the declarative and imperative process modeling approach. A case study is elaborated for a Chinese bulk port. Through investigation of the service departments and services involved, the process is decomposed into loosely-structured parts modeled by a declarative approach and highly structured parts modeled by an imperative approach. The model could be the start point for further logistics service process investigation. Future work could be conducted for conformance checking of the logistics service process using the model as a reference model.

\section{Acknowledgements}

This research is supported by the Natural Science Foundation of China under Grant Nos. KBA212004533. In addition, the authors would also like to thank the anonymous reviewers for their valuable comments.

\section{References}

Advanced Information Systems Engineering. In R. Andersen, J. Bubenko \& A. Sølvberg (Eds.), (Vol. 498, pp. 319-335): Springer Berlin / Heidelberg.

Aguilar-Saven, R.S. (2004). Business process modelling: Review and framework. International Journal of Production Economics, 90, 129-149. http://dx.doi.org/10.1016/S0925-5273(03)00102-6

Bichou, K., \& Gray, R. (2004). A logistics and supply chain management approach to port performance measurement. Maritime Policy \& Management, 31, 47-67. http://dx.doi.org/10.1080/0308883032000174454

Chapman, R.L., Soosay, C., \& Kandampully, J. (2003). Innovation in logistic services and the new business model: a conceptual framework. International Journal of Physical Distribution \& Logistics Management, 33, 630-650. http://dx.doi.org/10.1108/09600030310499295 
Chow, H.K.H., Choy, K., \& Lee, W. (2007). A dynamic logistics process knowledge-based system-An RFID multi-agent approach. Knowledge-Based Systems, 20, 357-372. http://dx.doi.org/10.1016/j.knosys.2006.08.004

Goedertier, S., \& Vanthienen, J. (2006). Business rules for compliant business process models, 85.

Hill, A.V., Collier, D.A., Froehle, C.M., Goodale, J.C., Metters, R.D., \& Verma, R. (2002). Research opportunities in service process design. Journal of Operations Management, 20, 189-202. http://dx.doi.org/10.1016/S0272-6963(01)00092-4

Krogstie, J., McBrien, P., Owens, R., \& Seltveit, A. (1991). Information systems development using a combination of process and rule based approaches.

Lai, K. (2004). Service capability and performance of logistics service providers. Transportation Research Part E: Logistics and Transportation Review, 40, 385-399. http://dx.doi.org/10.1016/j.tre.2004.01.002

Langley, C.J., \& Holcomb, M.C. (1992). Creating logistics customer value. Journal of Business Logistics, 13, 1-27.

Lohmann, N., Verbeek, E., \& Dijkman, R. (2009). Petri net transformations for business processes-a survey. Transactions on Petri Nets and Other Models of Concurrency, II, 46-63. http://dx.doi.org/10.1007/978-3-642-00899-3 3

Lu, R., \& Sadiq, S. (2007). A survey of comparative business process modeling approaches. Springer (pp. 82-94).

Mentzer, J.T., Flint, D.J., \& Hult, G.T.M. (2001). Logistics service quality as a segment-customized process. The Journal of Marketing, 82-104. http://dx.doi.org/10.1509/jmkg.65.4.82.18390

Mentzer, J.T., Rutner, S.M., \& Matsuno, K. (1997). Application of the means-end value hierarchy model to understanding logistics service value. International Journal of Physical Distribution \& Logistics Management, 27, 630-643. http://dx.doi.org/10.1108/09600039710188693

Pesic, M., Schonenberg, H.M., \& van der Aalst, W.M.P. (2007). Declare: Full support for loosely-structured processes. In IEEE, pp. 287-287.

Pesic, M., Schonenberg, H.M., \& Van der Aalst, W.M.P. (2009). Declare demo: a constraint-based workflow management system.

Reijers, H.A. (2003). Design and control of workflow processes: Business process management for the service industry. Springer-Verlag. http://dx.doi.org/10.1007/3-540-36615-6

Rodrigues, A.M., Stank, T.P., \& Lynch, D.F. (2004). Linking strategy, structure, process, and performance in integrated logistics. Journal of Business Logistics, 25, 65-94. http://dx.doi.org/10.1002/j.2158-1592.2004.tb00182.x 
Roh, H.S., Lalwani, C.S., \& Naim, M.M. (2007). Modelling a port logistics process using the structured analysis and design technique. International Journal of Logistics Research and Applications, 10, 283-302. http://dx.doi.org/10.1080/13675560701478240

Rutner, S.M., \& Langley Jr,C.J. (2000). Logistics value: definition, process and measurement. The International Journal of Logistics Management, 11, 73-82.

Stank, T.P., Keller, S.B., \& Daugherty, P.J. (2001). Supply chain collaboration and logistical service performance. Journal of Business Logistics, 22, 29-48. http://dx.doi.org/10.1002/j.2158-1592.2001.tb00158.x

Van der Aalst, W.M.P. (1998). Three good reasons for using a Petri-net-based workflow management system. Information and Process Integration in Enterprises, 428.

Van der Aalst, W.M.P., \& Ter Hofstede, A.H.M. (2005). YAWL: yet another workflow language. Information systems, 30, 245-275. http://dx.doi.org/10.1016/j.is.2004.02.002

van der Aalst, W.M.P., Pesic, M., \& Schonenberg, H. (2009). Declarative workflows: Balancing between flexibility and support. Computer Science-Research and Development, 23, 99-113. http://dx.doi.org/10.1007/s00450-009-0057-9

Van der Veeken, D.J.M., \& Rutten, W.G.M.M. (1998). Logistics service management: opportunities for differentiation. The International Journal of Logistics Management, 9, 91-98. http://dx.doi.org/10.1108/09574099810805861

Zur Muehlen, M., \& Indulska, M. (2010). Modeling languages for business processes and business rules: A representational analysis. Information systems, 35, 379-390. http://dx.doi.org/10.1016/j.is.2009.02.006

Journal of Industrial Engineering and Management, 2013 (www.jiem.org) 